This is an electronic reprint of the original article. This reprint may differ from the original in pagination and typographic detail.

Author(s): Helttunen, Kaisa; Galán, Albano; Ballester, Pablo; Bergenholtz, Johan; Nissinen, Maija

Title: $\quad$ Solid lipid nanoparticles from amphiphilic calixpyrroles

Year: $\quad 2016$

Version:

Please cite the original version:

Helttunen, K., Galán, A., Ballester, P., Bergenholtz, J., \& Nissinen, M. (2016). Solid lipid nanoparticles from amphiphilic calixpyrroles. Journal of Colloid and Interface Science, 464(February), 59-65. https://doi.org/10.1016/j.jcis.2015.11.012

All material supplied via JYX is protected by copyright and other intellectual property rights, and duplication or sale of all or part of any of the repository collections is not permitted, except that material may be duplicated by you for your research use or educational purposes in electronic or print form. You must obtain permission for any other use. Electronic or print copies may not be offered, whether for sale or otherwise to anyone who is not an authorised user. 


\title{
Solid lipid nanoparticles from amphiphilic calixpyrroles
}

Kaisa Helttunen ${ }^{1, *}$, Albano Galán ${ }^{2}$, Pablo Ballester ${ }^{2,3}$, Johan Bergenholtz ${ }^{4}$, and Maija Nissinen ${ }^{1}$

${ }^{1}$ University of Jyvaskyla, Department of Chemistry, Nanoscience Center, P.O. Box 35, FI40014 University of Jyvaskyla, Finland. e-mail: kaisa.j.helttunen@jyu.fi, +358 408054448.

${ }^{2}$ Institute of Chemical Research of Catalonia (ICIQ), Avgda. Països Catalans 16, 43007 Tarragona, Spain.

${ }^{3}$ Catalan Institution for Research and Advanced Studies (ICREA), Passeig Lluís Companys 23, 08010 Barcelona, Spain.

${ }^{4}$ Department of Chemistry and Molecular Biology, University of Gothenburg, SE-412 96 Göteborg, Sweden.

\begin{abstract}
Hypothesis

Macrocyclic amphiphiles form interesting self-assembling structures, including solid lipid nanoparticles, which have potential applications in drug encapsulation. Aryl-extended calixpyrroles, which act as anion binding hosts, are expected to form solid lipid nanoparticles, even though the alkyl chains have unusual perpendicular geometry with respect to the hydrophilic head group. The preparation conditions and the alkyl chain length should affect the size and stability of the particles.

Experiments

Solid lipid nanoparticles of two aryl-extended calixpyrroles with resorcinol walls and either meso-dodecyl or meso-methyl alkyl chains were compared. Ethanolic solutions of the calixpyrroles were mixed with water and the resulting nanoparticle dispersions were studied with dynamic light scattering and nanoparticle tracking analysis. The effect of different calixpyrrole/ethanol/water ratios on particle size was tested. The surface charge of the particles at different $\mathrm{pH}$ and $\mathrm{NaCl}$ concentration was determined by zeta potential measurements.
\end{abstract}




\section{Findings}

The meso-dodecyl calixpyrrole produced small nanoparticles with mean hydrodynamic diameters between $40-70 \mathrm{~nm}$ in $0.86-4.28 \mathrm{M}$ ethanol. The particles were stable in solution for several months. Particles prepared from meso-methyl calixpyrrole were larger and less stable. The smallest particles were obtained with low calixpyrrole concentration and calixpyrrole/ethanol ratio. Larger ethanol/water ratio induced broader particle size distributions. Increasing $\mathrm{pH}$ aided the stability of the particles due to increased negative surface charge.

\section{Keywords}

Amphiphile, calixpyrrole, dynamic light scattering, macrocycle, nanoparticle tracking analysis, solid lipid nanoparticle, zeta potential

\section{Introduction}

Calixpyrroles are macrocyclic tetrapyrroles known for their binding affinity towards halide anions. ${ }^{1,2,3}$ The four pyrrole rings are linked by meso-carbon bridges, which carry eight substituents, such as alkyl chains or aryl substituents in the aryl-extended calixpyrroles. The three dimensional structure of an aryl-extended calixpyrrole (Fig. 1) shows the cone shaped anion binding site formed by the pyrrole $\mathrm{NH}$ groups and the aromatic walls. The upper rim of the cavity is lined with hydroxyl groups, and the alkyl substituents attached to the mesocarbons extend to the sides of the molecule giving it unique amphiphilic properties.

Aryl-extended calixpyrroles have interesting applications as supramolecular capsules ${ }^{4}$ and as ion transport agents. ${ }^{5}$ The meso-methyl calixpyrrole 2 (Fig. 2) with resorcinol walls selfassemble in the solid state into a hexameric cage ${ }^{6}$ reminiscent of the hexameric resorcinarene and pyrogallarene capsules. ${ }^{7}$ An assembly into capsules was also observed in solution for amphiphilic meso-undecyl derivative $\mathbf{1 b}$, which formed a hexameric capsule in apolar solution. ${ }^{8}$ In addition, the solid state structure of amphiphilic meso-dodecyl derivative $\mathbf{1}$ consists of alternating lipophilic and hydrophilic layers. ${ }^{9}$ However, the aggregation properties of amphiphilic calixpyrroles in aqueous solutions have not been studied.

Nanoparticles composed of solid lipids, such as triglycerides or waxes, are called solid lipid nanoparticles (SLN). ${ }^{10}$ Solid lipid nanoparticles are typically between $150-300 \mathrm{~nm}$ in 

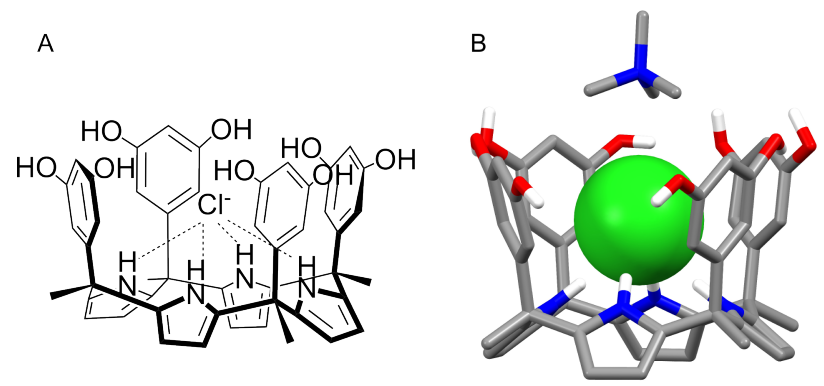

Figure 1. A schematic drawing of meso-methyl calixpyrrole in a cone conformation, where all $\mathrm{NH}$ hydrogens point towards a complexed chloride anion (A), and a crystal structure of calixpyrrole tetramethylammonium chloride complex (B, CCDC code RIBBIO). ${ }^{6}$ The chloride anion is shown as a CPK model and only $\mathrm{OH}$ and $\mathrm{NH}$ hydrogens are shown for clarity.

diameter and they have been developed as drug encapsulating structures for pharmaceutical and cosmetic products. SLNs can be prepared on a laboratory scale by a solvent replacement method, also known as a solvent diffusion method, where the amphiphile or lipid is first dissolved in an organic water-miscible solvent and then mixed with water. ${ }^{11}$ The method has been applied for preparation of SLNs from macrocyclic amphiphiles, such as modified cyclodextrins, ${ }^{12}$ calixarenes ${ }^{13,14}$ and resorcinarenes. ${ }^{15,16}$ Macrocyclic amphiphiles are interesting building blocks for nanoparticle preparation, since they have unique selfassembling properties ${ }^{17}$ and they form inclusion complexes with lipophilic guest molecules within their cavities. ${ }^{18}$

Typical examples of non-ionic amphiphiles are para-acyl calix[4]arenes (3) and $C$-undecyl resorcinarene (4), which form 130-150 nm solid lipid nanoparticles in THF/water solution. ${ }^{13,15}$ Both compounds consist of four aromatic rings connected by methylene carbons (Fig. 2). Calixarenes have four hydroxyl groups at the narrow rim of the aromatic cavity, whereas resorcinarenes have eight hydroxyl groups at the wider rim of the cavity providing larger cross-sectional area of the hydrophilic group. Interestingly, the stirring speed did not affect the particle size, whereas, an increase in the concentration of the amphiphile in an organic solvent increased the particle size of calix[4]arene and resorcinarene SLNs. In case of para-dodecanoyl calix[4]arene (3b), preparation in ethanol and THF produced similar particle size while preparation in acetone or methanol increased the particle size by $30-40 \%$. Small, sub-100 nm particles have only been obtained with para-acyl calix[9]arenes bearing paradodecanoyl and para-tetradecanoyl chains. ${ }^{19}$

The preparation method of solid lipid nanoparticles - fast precipitation with an antisolvent implies that they are non-equilibrium structures. Long equilibrium times of the nanoparticle systems leads to kinetically trapped states where thermodynamics is not driving the self- 
assembly. ${ }^{20}$ The process is similar to spontaneous emulsification, which has been described for preparation of polymeric nanoparticles and nanocapsules in a dilute concentration regime. ${ }^{21}$ Regarding the use of novel amphiphiles as molecular building blocks, it is important to elucidate how structural factors of the amphiphiles in conjunction with the preparation parameters affect the structure and stability of the nanoparticles. ${ }^{22}$

In the present work, resorcinol-extended meso-dodecyl calixpyrrole $\mathbf{1}$ was found to spontaneously aggregate into very small and stable nanoparticles without mechanical processing, such as sonication. The particles were studied with dynamic light scattering ${ }^{23}$ and a relatively new technique, nanoparticle tracking analysis, ${ }^{24}$ which are convenient methods for studying sub-micrometer nanoparticles in solutions. The results are presented as a case study of the first calixpyrrole-based solid lipid nanoparticles.

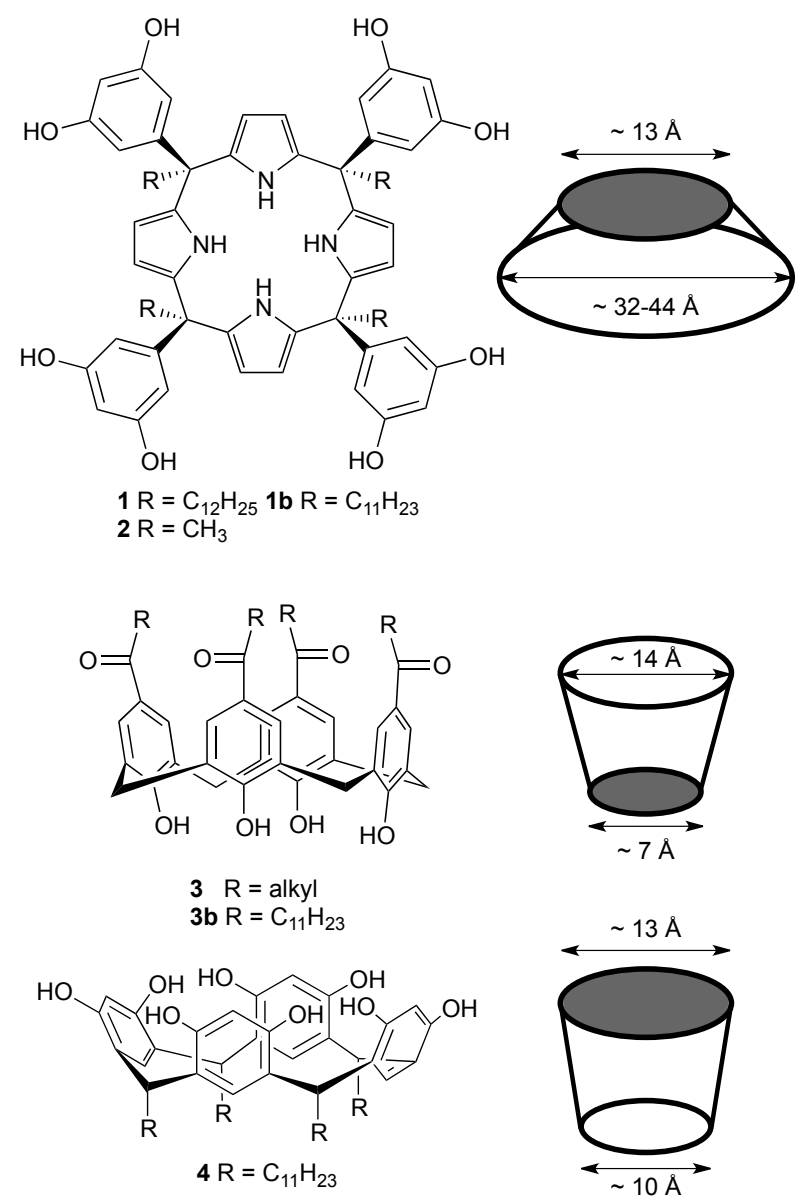

Figure 2. Calixpyrroles (1 and 2), and structurally related macrocycles, para-acyl calixarene (3), and $C$-undecyl resorcinarene (4). The relative shape of each amphiphile is shown as a drawing with a grey circle representing the cross-sectional area of the hydrophilic head group. 


\section{Materials and methods}

\section{Chemicals and synthesis}

$\mathrm{NaCl}$ (Riedel-de Haën, 99.8 \%), NaOH (Scharlau, 99 \%), ethanol (Solveco Aa, 99.7 \%) were used as received. Calixpyrroles 1 and $\mathbf{2}$ were prepared according to reported procedures ${ }^{6,9}$ by acid catalyzed condensation of pyrrole with the appropriate ketones. Briefly, into a solution of pyrrole $(3.6 \mathrm{mmol})$ in methanol $(6 \mathrm{~mL})$, methanesulfonic acid $(10.8 \mathrm{mmol})$ and 1-(3,5dihydroxyphenyl)tridecan-1-one (3.6 $\mathrm{mmol})$ or methyl 3,5-dihydroxyphenylketone (3.6 mmol) were added, and the reaction was carried overnight at room temperature protected from light. The product was purified with chromatography using a $\mathrm{SiO}_{2}$ column (dichloromethane:ethyl acetate 6:4), and recrystallized from acetonitrile (yield $19 \%$ and $3 \%$ for $\mathbf{1}$ and 2, respectively). The purity was assessed with ${ }^{1} \mathrm{H}$ NMR to be $>95 \%$.

\section{Particle preparation}

The particles were prepared by dissolving $1.0-2.0 \mathrm{mg}$ of calixpyrrole $\mathbf{1}$ or $\mathbf{2}$ in $100-500 \mu \mathrm{l}$ of ethanol (99.7\%), and adding the solution dropwise to $1.5-9.5 \mathrm{~mL}$ of Milli-Q water $(>18$ $\mathrm{M} \Omega \cdot \mathrm{cm}, \mathrm{pH} 4-5$ ) using $300 \mathrm{rpm}$ magnetic stirring and a $10 \mathrm{~mm}$ stirring bar. The samples with 0.1-10.0 mM NaCl were prepared by adding appropriate amounts of $\mathrm{NaCl}$ to the water phase. The samples with $\mathrm{NaOH}$ were prepared by adding appropriate amounts of $\mathrm{NaOH}$ solution in water phase and their $\mathrm{pH}$ was determined with indicator paper. The final $\mathrm{pH}$ of the solution depends on $\mathrm{NaOH}$ concentration and the steps in dilution due to the acidic $\mathrm{pH}$ of the purified water.

\section{DLS and $\zeta$-potential measurements}

Dynamic light scattering was carried out on the particle suspensions in polystyrene cuvettes using a Malvern Zetasizer nano-ZS instrument at a $173^{\circ}$ scattering angle using a $633 \mathrm{~nm}$ laser at $20.0{ }^{\circ} \mathrm{C}$. The solvent refractive index and viscosity for each ethanol-water mixture was determined using the Solvent builder function of the Zetasizer software (version 7.10) as tabulated in Table 1 . The viscosity values were checked against literature. ${ }^{25}$ The samples were diluted, when necessary, into a suitable ethanol-water mixture. A second-order cumulant analysis was performed from which the hydrodynamic diameter was determined from the first cumulant and a polydispersity index (PdI) was determined from the second cumulant divided by the square of the first cumulant. The aggregation numbers for the particles were estimated according to $N=\frac{V_{p}}{V_{m}}=\frac{4 \cdot \pi \cdot r^{3}}{3 \cdot V_{m}}$, where $\mathrm{V}_{\mathrm{p}}$ is the volume of a spherical particle, $\mathrm{V}_{\mathrm{m}}$ is the monomer volume and $\mathrm{r}$ is the mean hydrodynamic radius. 
The zeta $(\zeta)$-potential was measured with the same instrument using folded capillary cells at $25{ }^{\circ} \mathrm{C}$. Electrophoretic mobilities were converted to $\zeta$-potentials using Smoluchowski's equation, which is valid for high salt concentrations. In addition, $\zeta$-potentials obtained using Henry's equation, which better describe the $\zeta$-potentials over a larger range of ionic strength are shown for comparison. The data are reported as the averages of three measurements with standard deviation.

Table 1.The viscosity values used for DLS and NTA measurements.

\begin{tabular}{lllllll}
\hline EtOH $(\mathrm{M})$ & $\mathrm{T}\left({ }^{\circ} \mathrm{C}\right)$ & $\eta(\mathrm{cP})$ & $\mathrm{T}\left({ }^{\circ} \mathrm{C}\right)$ & $\eta(\mathrm{cP})$ & $\mathrm{T}\left({ }^{\circ} \mathrm{C}\right)$ & $\eta(\mathrm{cP})$ \\
\hline 0.43 & 19.0 & 1.1139 & 20.0 & 1.0895 & 21.0 & 1.0644 \\
0.86 & 19.0 & 1.2034 & 20.0 & 1.1773 & 21.0 & 1.1529 \\
1.73 & 19.0 & 1.4184 & 20.0 & 1.3938 & 21.0 & 1.3692 \\
2.83 & 19.0 & 1.7440 & 20.0 & 1.7179 & 21.0 & 1.6929 \\
4.28 & 19.0 & 2.1918 & 20.0 & 2.1672 & 21.0 & 2.1426 \\
\hline
\end{tabular}

\section{NTA measurements}

Nanoparticle tracking analysis is based on illuminating a very dilute sample dispersion $\left(10^{7}-\right.$ $10^{10}$ particles per $\mathrm{mL}$ ) with a laser beam, and imaging scattered light from individual particles under a microscope. The Brownian motion of a spherical particle is linked to the diffusion coefficient $D$ by the Stokes-Einstein relation ${ }^{26} D=\frac{k_{B} \cdot T}{6 \cdot \pi \cdot \eta \cdot r}$, where $k_{B}$ is Boltzmann's constant, $T$ is the temperature, $\eta$ is the viscosity of the solvent, and $r$ is the particle radius. The mean square displacement of a particle in Brownian motion increases linearly with time $t .^{27}$ Specifically, when the movement of the particle is observed in two dimensions, the mean square displacement is ${ }^{28}\left\langle x^{2}+y^{2}\right\rangle=4 \cdot D \cdot t=\frac{2 \cdot k_{B} \cdot T \cdot t}{3 \cdot \pi \cdot \eta \cdot r}$. Thus, by measuring the mean square displacement of individual particles in a given time interval, a histogram of diffusion coefficients can be determined from which a number-weighted size distribution can be extracted.

The detection limit for NTA has been estimated as approximately $50 \mathrm{~nm}$ for relatively weakly scattering materials, such as polystyrene and silica, and approximately $15 \mathrm{~nm}$ for highly scattering materials, such as gold. ${ }^{28}$

The measurements were carried out on the NTA system LM10 composed of a flow cell housed in an anodised aluminium alloy casing fitted with metallized optical glass with 
polyacetal window and fluorocarbon elastomer seal. The light source was a solid-state, singlemode laser diode (radiation output maximum power $<50 \mu \mathrm{W}, 635-\mathrm{nm}$ continuous wave, maximum power $<35 \mathrm{~mW}$ ). The microscope was equipped with a Marlin F-033B camera (Allied Vision Technologies GmbH, Stadtroda, Germany). The data analysis was made with Nanosight ${ }^{T M}$ software (version 2.3, 2012 NanoSight Ltd).

The measurements were done by filling the flow cell with diluted sample suspension and recording a 1 minute video. The procedure was repeated seven times for each concentration and the size distribution from each video was averaged. The sample concentration was chosen so as to maximize the number of the particles tracked (typically 100-10000 times diluted suspensions in a suitable ethanol-water mixture). The camera and processing parameters were chosen for each sample to allow for the detection of the weakly scattering small particles. The NTA measurements were done at room temperature. Viscosity was corrected for each solvent mixture according to Table 1. Errors caused by the temperature drifting during the measurements were estimated to be $1 \mathrm{~nm}$ per $0.4^{\circ} \mathrm{C}$, leading to a maximum error of $\pm 0.6 \mathrm{~nm}$ for the particle diameters determined.

\section{Results and discussion}

Calixpyrroles $\mathbf{1}$ and $\mathbf{2}$ are well soluble in ethanol, and the meso-methyl calixpyrrole $\mathbf{2}$ is soluble in water at basic $\mathrm{pH}$ when the hydroxyl groups are deprotonated. The deprotonated calixpyrrole 2 did not have surfactant properties as tested with optical tensiometry $(\mathrm{pH} 10,0.5$ $\mathrm{mg} / \mathrm{mL}$ ) due to lack of hydrophobic chains. The amphiphilic derivative $\mathbf{1}$ was not soluble in water. The hydrophilic-lipophilic balance of the calixpyrroles was estimated with Griffin's method $^{29}$ resulting in 2.8 and 4.9 for $\mathbf{1}$ and $\mathbf{2}$, respectively. Thus, both molecules fall clearly into the hydrophobic category, as para-acyl calixarenes and $C$-undecyl resorcinarene.

\section{Solid lipid nanoparticles}

Due to the small amount of calixpyrroles available, only small-scale preparation of the calixpyrrole SLNs was feasible. Therefore, some modifications were made to the typical solvent-diffusion method. The mixing order of the phases was reversed by adding organic phase dropwise to water and the solvent evaporation step was omitted. Therefore, a solvent system which would not dissolve plastic cuvettes was required. Among the water-miscible solvents typically used for SLN preparation (acetone, ethanol, methanol and $\mathrm{THF}^{13}$ ), ethanol 
is a benign solvent, which dissolves the investigated calixpyrroles well, and was therefore chosen for the particle studies.

Addition of ethanolic solution of calixpyrrole $\mathbf{1}$ in purified water with gentle stirring immediately produced nanoparticles, which were stable in solution even after several months. The mean hydrodynamic diameters were measured with DLS (Table 2). Calixpyrrole 1 formed particles with mean hydrodynamic diameters below $100 \mathrm{~nm}$ (39-66 nm, samples 1-1 - 1-4), when ethanol concentrations of 0.86-4.28 M were used. At the same conditions, calixpyrrole 2 formed particles larger than $100 \mathrm{~nm}$ with large polydispersity (Table 2), indicating that the lack of long alkyl chains makes the compound much less suitable for the SLN preparation.

The smallest particle sizes for 1 were obtained with small calixpyrrole/ethanol mole ratios $\left(\mathrm{n}_{\mathrm{cp}} / \mathrm{n}_{\mathrm{EtOH}}<1 \times 10^{-4}\right)$ and small calixpyrrole mole fractions $\left(X_{\mathrm{cp}} \sim 10^{-6}\right)$, and the size increased when calixpyrrole and ethanol concentrations were increased. These parameters are related to the solubility of the calixpyrrole in the mixture. Particle preparation was repeated at least twice under identical conditions and the most reproducible results were obtained for sample 1-1 in dilute conditions (standard deviation $0.7 \mathrm{~nm}$ ). In addition, sample 1-4 in 4.28 M ethanol gave the highest variation for diameters (standard deviation $5.4 \mathrm{~nm}$ ). The maximum stable concentration of calixpyrrole 1 in the system was tested in $0.43 \mathrm{M}$ ethanol (1-15-1-20, Fig. $\mathrm{S}-1^{\dagger}$ ) where precipitation of the calixpyrrole was observed visually in the sample 1-15 at $X_{\mathrm{cp}}=$ $2.7 \times 10^{-5}$ and $\mathrm{n}_{\mathrm{cp}} / \mathrm{n}_{\mathrm{EtOH}}=3.4 \times 10^{-3}$.

Nanoparticle tracking analysis (NTA) was used as a complementary method for measuring the hydrodynamic sizes and size distributions of the particles. Since nanoparticle tracking analysis is not an ensemble method, each observed scatterer being sized individually, it is better suited for polydisperse samples than DLS. The NTA data for the samples prepared in different ethanol concentrations, 1-1 $(0.86 \mathrm{M}), \mathbf{1 - 3}(2.83 \mathrm{M})$ and 1-4 $(4.28 \mathrm{M})$, confirmed the trend of increasing size observed with DLS (Fig. 3). In addition, NTA measurements indicated that the width of the size distribution increases in the order of 1-1 $<1-3<1-4$. However, it should be noted that the smallest particles below $50 \mathrm{~nm}$ were difficult to image due to their weak scattering power, which shifts the mean diameter of the distribution to larger size in comparison to DLS. In addition, small, rapidly diffusing particles have short

\footnotetext{
${ }^{\dagger}$ See ESI for details.
} 
track lengths during which they remain illuminated by the laser, which can result in artificial broadening of the size distribution. ${ }^{30}$

Table 2. The mean hydrodynamic diameters (Z-average) for SLN samples of 1 and $\mathbf{2}$ measured with DLS. The data for $\mathbf{1}$ are given as an average of replicate samples (2-5) with standard deviation, and for $\mathbf{2}$ as a single point since the particles were prepared only once.

\begin{tabular}{lllllll}
\hline Sample & $\begin{array}{l}X_{c p} \\
\left(\times 10^{-6}\right)\end{array}$ & $\begin{array}{l}\text { EtOH } \\
(\mathrm{M})\end{array}$ & $\begin{array}{l}\left.\mathrm{n}_{\mathrm{cp}} / \mathrm{n}_{\text {EtOH }} \times 10^{-5}\right) \\
(\times 1 \mathrm{~nm})\end{array}$ & $\begin{array}{l}\text { Diameter } \\
(\mathrm{nm})\end{array}$ & $\begin{array}{l}\mathrm{PdI} \\
\left(\times 10^{4}\right)\end{array}$ \\
\hline $\mathbf{1 - 1}$ & 1.3 & 0.86 & 8.2 & $39.5 \pm 0.7$ & $0.21 \pm 0.01$ & $1.3^{\mathrm{a}}$ \\
$\mathbf{1 - 2}$ & 7.2 & 2.83 & 12.4 & $50.5 \pm 2.1$ & $0.18 \pm 0.04$ & $2.7^{\mathrm{a}}$ \\
$\mathbf{1 - 3}$ & 14.9 & 2.83 & 25.9 & $62.0 \pm 2.8$ & $0.24 \pm 0.06$ & $5.0^{\mathrm{a}}$ \\
$\mathbf{1 - 4}$ & 15.3 & 4.28 & 16.5 & $66.0 \pm 5.4$ & $0.17 \pm 0.04$ & $6.0^{\mathrm{a}}$ \\
\hline $\mathbf{2 - 1}$ & 1.4 & 0.86 & 8.7 & 198 & 0.23 & $340^{\mathrm{b}}$ \\
$\mathbf{2 - 2}$ & 2.9 & 1.71 & 8.7 & 137 & 0.26 & $110^{\mathrm{b}}$ \\
$\mathbf{2 - 3}$ & 16.2 & 4.28 & 17.0 & 197 & 0.57 & $330^{\mathrm{b}}$
\end{tabular}

${ }^{\mathrm{a}}$ Aggregation numbers were estimated by using the mean diameter and a monomer volume of $2.5 \mathrm{~nm}^{3}$. ${ }^{\mathrm{b}} \mathrm{A}$ monomer volume of $1.2 \mathrm{~nm}^{3}$ was used.
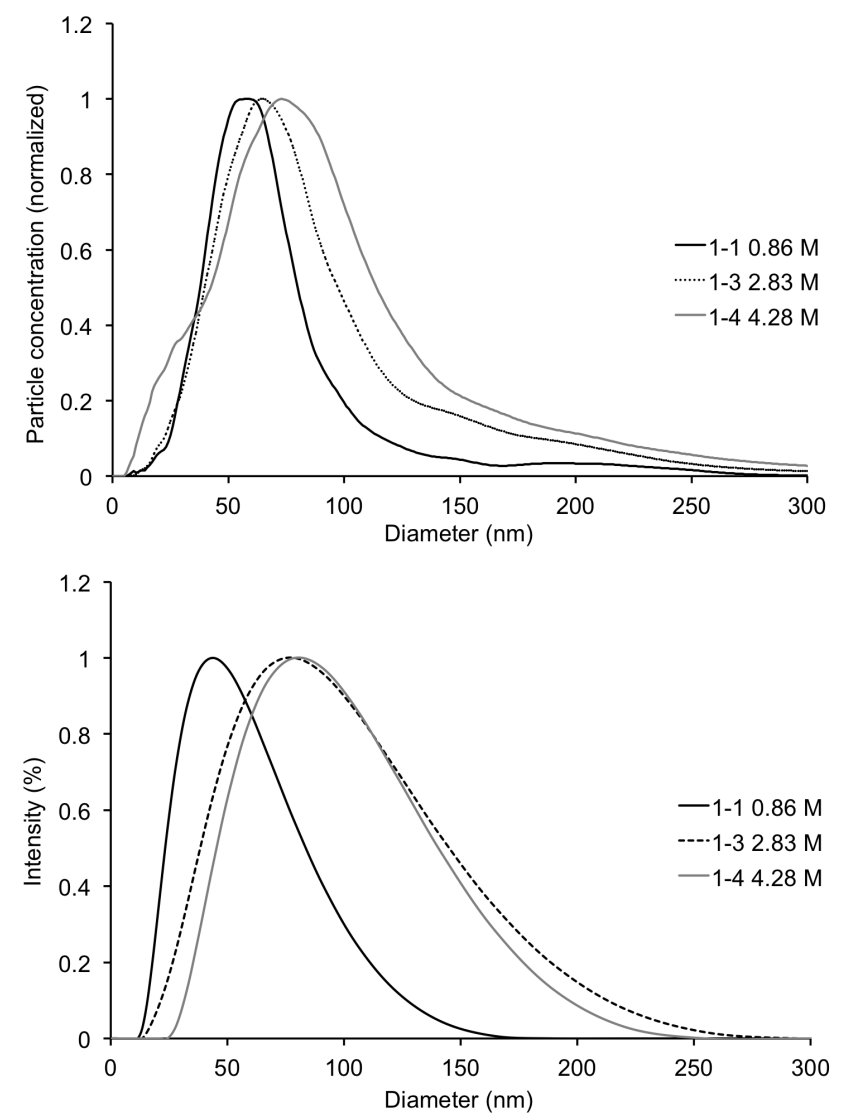

Figure 3. Particle size distributions from the NTA measurement for the samples 1-1, 1-3 and 1-4 prepared in different ethanol concentrations (top). DLS intensity based size distribution for the same samples (bottom). 
Some structural features of the nanoparticles can be deduced from the molecular structure of the calixpyrrole 1 and the observed particle properties. The shape of the molecule with long alkyl chains oriented to the sides of the polar head group neither favors small spherical micelles nor vesicle structures. The packing parameter was estimated from the molecular dimensions of $\mathbf{1}$. The minimum value is 0.74 when the molecule is forced into an elongated conformation (alkyl chains at a $34^{\circ}$ angle relative to the symmetry axis), and grows rapidly to reach values greater than 1 when the alkyl chains approach more relaxed, perpendicular conformations. An ideal packing parameter for surfactants is 0.33 in spherical micelles, 0.5 for infinite cylinders, and 1 for planar bilayers. ${ }^{31}$ Packing parameter larger than 1 favors inverted cylinders and micelles. The aggregation numbers $(\mathrm{N})$ calculated from the hydrodynamic diameter and minimum molecular volume were large, on the order of $\sim 10^{4}-$ $10^{5}$ (Table 2), which is typical for non-ionic surfactants in wormlike micelles. ${ }^{32}$ However, scanning electron microscopy of the dried samples revealed spherical particles (Fig. S-2 ${ }^{\dagger}$ ), as in typical solid lipid nanoparticle samples. Even though it is difficult to estimate the level of molecular organization inside the particles, it is reasonable to assume that the hydrophilic groups are facing towards the water phase at the particle surface leaving the anion binding cavities exposed. Thus, adding $\mathrm{NaCl}$ to the water phase can result in binding of chloride inside the calixpyrrole cavities; however, adding $\mathrm{NaCl}$ will also lead to screening of any surface charge causing a decrease of the barrier to aggregation due to van der Waals forces.

When SLNs were prepared in dilute $\mathrm{NaCl}$ solutions $(0.1-50.0 \mathrm{mM} \mathrm{NaCl}$, Table 3) DLS measurements indicated an increase in the hydrodynamic particle diameter in $0.86 \mathrm{M}$ ethanol (1-5 - 1-9) and in 4.28 $\mathrm{M}$ ethanol (1-10 - 1-14). The samples prepared in $50 \mathrm{mM} \mathrm{NaCl}$ started to precipitate quickly. Ideally, the hydrodynamic size and the intensity-weighted mean size in DLS are the same for monodisperse samples, which is seen for samples 1-5 and 1-6. For the samples 1-7 and 1-8 with 5 and $10 \mathrm{mM} \mathrm{NaCl}$, respectively, the hydrodynamic size is slightly smaller than the intensity-based mean size (Fig. 4). This may be caused by the cumulant analysis being constrained to the initial decay of the correlation function, which may be dominated by smaller-size particles. The particles were also analyzed with NTA, which showed that the mean particle sizes were slightly increased upon addition of salt, and the size distributions broadened for the samples 1-7 and 1-8 (Fig. 4). However, the number of observed large $(>100 \mathrm{~nm}$ ) particles in the NTA measurements was low giving smaller mean hydrodynamic diameters than DLS. 
Table 3. Mean hydrodynamic diameters (Z-average) for $\mathbf{1}$ prepared in $\mathrm{NaCl}$ solutions.

\begin{tabular}{|c|c|c|c|c|c|c|}
\hline Sample & $\begin{array}{l}X_{c p} \\
\left(\cdot 10^{-6}\right)\end{array}$ & $\begin{array}{l}\text { EtOH } \\
\text { (M) }\end{array}$ & $\begin{array}{l}\mathrm{n}_{\mathrm{cp}} / \mathrm{n}_{\mathrm{EtOH}} \\
\left(\cdot 10^{-5}\right)\end{array}$ & $\begin{array}{l}\mathrm{NaCl} \\
(\mathrm{mM})\end{array}$ & $\begin{array}{l}\text { Diameter } \\
(\mathrm{nm})\end{array}$ & PdI \\
\hline $1-5$ & 1.3 & 0.86 & 8.2 & 0.1 & 37 & 0.26 \\
\hline $1-6$ & 1.3 & 0.86 & 8.2 & 1.0 & 42 & 0.15 \\
\hline $1-7$ & 1.3 & 0.86 & 8.2 & 5.0 & 73 & 0.09 \\
\hline $1-8$ & 1.3 & 0.86 & 8.2 & 10.0 & 88 & 0.05 \\
\hline $1-9$ & 1.3 & 0.86 & 8.2 & 50.0 & $-{ }^{a}$ & $-{ }^{a}$ \\
\hline $1-10$ & 15.3 & 4.28 & 16.5 & 0.1 & 60 & 0.15 \\
\hline 1-11 & 15.3 & 4.28 & 16.5 & 1.0 & 55 & 0.15 \\
\hline $1-12$ & 15.3 & 4.28 & 16.5 & 5.0 & 77 & 0.10 \\
\hline 1-13 & 15.3 & 4.28 & 16.5 & 10.0 & 102 & 0.03 \\
\hline 1-14 & 15.3 & 4.28 & 16.5 & 50.0 & 384 & 0.11 \\
\hline
\end{tabular}

${ }^{\mathrm{a}}$ Sample precipitated.
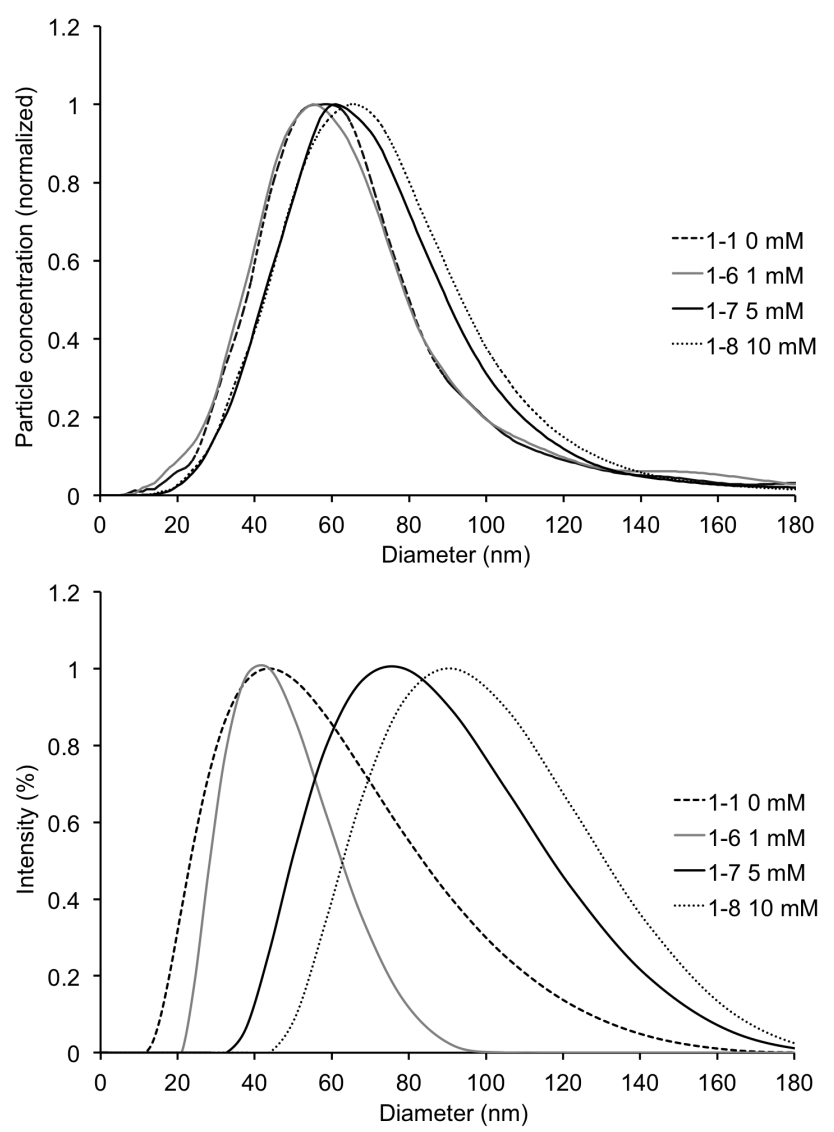

Figure 4. NTA size distributions for the samples prepared in $0.0 \mathrm{mM}(\mathbf{1}-1), 1.0 \mathrm{mM}(\mathbf{1}-6), 5.0 \mathrm{mM}(\mathbf{1}-7)$, and $10.0 \mathrm{mM}(\mathbf{1 - 8}) \mathrm{NaCl}$ solution in $0.86 \mathrm{M}$ ethanol (top). DLS intensity based size distributions for the same samples (bottom). 


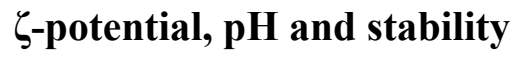

The stability of the nanoparticles was monitored by measuring the hydrodynamic diameter of each sample with DLS (Fig. S-3 $3^{\dagger}$ ), and visually assessing the appearance of the sample for precipitation. The particles prepared from amphiphilic calixpyrrole 1 were stable up to several months in solution at room temperature. The particles in sample 1-1 maintained almost constant diameter, and the samples 1-2, 1-3 and 1-4 with higher ethanol concentrations showed a slight decrease in the particle size during 60 days. It should be noted that the sizes are not corrected for changes in solvent viscosity induced by possible evaporation of ethanol during storage, which may account for some of the apparent decrease in the particle diameters. In contrast, meso-methyl calixpyrrole 2 started to crystallize out of the SLN suspension after a few weeks.

The stability of the solid lipid nanoparticles against aggregation arises from electrostatic repulsion. Calixpyrroles are neutral molecules below the deprotonation $\mathrm{pH}$ of phenolic hydroxyl groups ( $\mathrm{pK}_{\mathrm{a}} 9.15$ for resorcinol). ${ }^{33}$ As discussed above, calixpyrroles attract anions more strongly than cations, which is expected to give a negative surface charge.

The $\zeta$-potential was measured for SLN sample 1-7, which was prepared in $5 \mathrm{mM} \mathrm{NaCl}$ and adjusted to different $\mathrm{pH}$ with $\mathrm{NaOH}$ such that a constant $10 \mathrm{mM} \mathrm{Na}{ }^{+}$concentration was maintained through addition of $\mathrm{NaCl}$. Data indicated that the particles had a negative $\zeta$ potential as expected (Table 4). In addition, increase of the $\mathrm{pH}$ slightly to 7-9 increased the $\zeta$ potential of the particles significantly from $-42 \mathrm{mV}$ to $-76 \mathrm{mV}$. The $\zeta$-potential values converted with Henry's equation show a similar trend but with slightly higher values, as expected at an ionic strength of $10^{-2} \mathrm{M}^{34}$ At higher $\mathrm{pH}$ a $-60 \mathrm{mV}$ potential was obtained. This can likely be explained by increasing deprotonation of the resorcinol groups, and less $\mathrm{Cl}^{-}$ being taken up at the particle surface at higher $\mathrm{pH}$ due to lower $\mathrm{NaCl}$ concentration. The addition of 1-2 $\mathrm{mM}$ of $\mathrm{NaOH}$ also caused a slight decrease of the hydrodynamic diameters of the particles, which increases their electrophoretic mobility and the associated $\zeta$-potential.

The relationship between the stability of the SLN suspensions and their surface charge was tested by adding $\mathrm{NaCl}$ solution to the mixtures and following the hydrodynamic diameters with DLS (Fig. S-4 $4^{\dagger}$ ). Sample 1-7-1 at $\mathrm{pH} 4$ started to aggregate when $20 \mathrm{mM} \mathrm{NaCl}$ was added. At pH 7 and pH 9 the particle size did not significantly increase even in $154 \mathrm{mM}$ $\mathrm{NaCl}$. Thus, the critical coagulation concentration increased significantly at the higher $\mathrm{pH}$, which in turn correlates with the higher negative surface charge. 


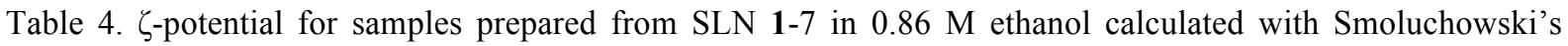
equation and with Henry's equation for comparison.

\begin{tabular}{llllllll}
\hline Sample & $\begin{array}{l}\mathrm{NaCl} \\
(\mathrm{mM})\end{array}$ & $\begin{array}{l}\mathrm{NaOH} \\
(\mathrm{mM})\end{array}$ & $\mathrm{pH}$ & $\begin{array}{l}\zeta^{\mathrm{a}} \\
(\mathrm{mV})\end{array}$ & $\begin{array}{l}\zeta^{\mathrm{b}} \\
(\mathrm{mV})\end{array}$ & $\begin{array}{l}\text { Diameter } \\
(\mathrm{nm})\end{array}$ & $\mathrm{PdI}$ \\
\hline $\mathbf{1 - 7 - 1}$ & 10 & 0 & 4.0 & $-42(4)$ & $-49(5)$ & 69 & 0.09 \\
$1-7-2$ & 9 & 1 & 7.0 & $-76(2)$ & $-90(2)$ & 63 & 0.08 \\
$1-7-3$ & 8 & 2 & 9.0 & $-70(1)$ & $-83(1)$ & 63 & 0.08 \\
$1-7-4$ & 7 & 3 & 9.5 & $-61(1)$ & $-72(2)$ & 66 & 0.08 \\
$1-7-5$ & 6 & 4 & 10.0 & $-60(3)$ & $-71(4)$ & 68 & 0.07 \\
$1-7-6$ & 5 & 5 & 11.0 & $-59(3)$ & $-70(4)$ & 70 & 0.05 \\
\hline
\end{tabular}

${ }^{a}$ Smoluchowski's equation, ${ }^{b}$ Henry's equation.

Monodisperse particle distributions with a large portion of the monomers on the particle surface would be more suitable for applications, such as encapsulating hydrophobic molecules within the particle matrix. Thus, the possibility to narrow the size distribution of the solid lipid nanoparticles was also explored. An attempt to ionize the calixpyrrole molecules during the preparation of SLNs was made using dilute $\mathrm{NaOH}$ solution. As expected, smaller hydrodynamic diameters, below $30 \mathrm{~nm}$ in $0.86 \mathrm{M}$ ethanol, were obtained (Table S- $2^{\dagger}$ ). However, the size distributions became multimodal indicating the presence of large aggregates that scattered strongly. Another experiment with the sample 1-4 in $4.28 \mathrm{M}$ ethanol was made by diluting the sample in $\mathrm{NaOH}$ solution at $\mathrm{pH}$ 8. A decrease in the hydrodynamic diameter to $54 \mathrm{~nm}$ was observed within one day.

\section{Conclusions}

Amphiphilic calixpyrroles formed solid lipid nanoparticles when ethanol solutions of the calixpyrroles were mixed with water. Comparison of two aryl-extended calixpyrrole derivatives indicated that long alkyl chains (meso-dodecyl) are needed to produce small $<100$ $\mathrm{nm}$ particles, which are stable for several months in solution. This size regime has rarely been obtained using related macrocyclic amphiphiles, which generally produce larger than $100 \mathrm{~nm}$ solid lipid nanoparticles. ${ }^{22}$ The size and size distribution of the particles can be decreased by using dilute calixpyrrole suspension and smaller ethanol concentration. The $\zeta$-potential measurements showed that the particles were stabilized by a negative surface charge even at 
neutral and slightly acidic $\mathrm{pH}$. This is likely due to the complexation of negatively charged chloride ions within the calixpyrrole cavity.

The solubility of the molecules and stability of the nanoparticles suggests that they are best described as non-equilibrium aggregates, which are formed rapidly during mixing by the hydrophobic effect. The process is similar to spontaneous emulsification, also known as the Ouzo effect, which occurs when a large amount of water is mixed with a dilute solution of oil in a hydrophilic solvent. ${ }^{21}$ It was reported that smaller particle sizes were obtained by increasing the solvent to oil ratio, which was also observed for the calixpyrrole solid lipid nanoparticles. Structurally related $C$-undecyl resorcinarene ${ }^{15}$ and para-dodecanoyl calixarene $^{13}$ showed a similar trend in solvent to amphiphile ratio.

In the future, calixpyrrole nanoparticles could be used for encapsulating hydrophobic drugs. The organization of the calixpyrroles in the nanoparticles would be interesting to elucidate using, for example, fluorescent dyes. In addition, the anion binding properties of the calixpyrrole cavities could be utilized for coating the particles with targeting groups.

\section{Acknowledgements}

Dr. Julián Alberto Gallego-Urrea is acknowledged for his help with the NTA measurements, Dr. Romain Bordes for surface tension measurements, and M.Sc. Jeanette Ulama for valuable discussions. Academy of Finland (project 21000019111), Oskar Öflunds Stiftelse, The Alfred Kordelin Foundation, and University of Jyvaskyla are acknowledged for funding.

\section{References}

${ }^{1}$ P. A. Gale, J. L. Sessler, V. Král, and V. Lynch, Calix[4]pyrroles: Old Yet New AnionBinding Agents, J. Am. Chem. Soc., 1996, 118, 5140-5141; P. A. Gale, J. L. Sessler, and V. Král, Calixpyrroles, Chem. Commun., 1998, 1-8.

${ }^{2}$ A. Aydogan, D. J. Coady, V. M. Lynch, A. Akar, M. Marquez, C. W. Bielawski, and J. L. Sessler, Poly(methyl methacrylate)s with pendant calixpyrroles: polymeric extractants for halide anion salts, Chem. Commun., 2008, 1455-1457.

${ }^{3}$ G. Gil-Ramírez, E. C. Escudero-Adán, J. Benet-Buchholz, and P. Ballester, Quantitative Evaluation of Anion- $\pi$ Interactions in Solution, Angew. Chem. Int. Ed., 2008, 47, 4114-4118. 
${ }^{4}$ P. Ballester, Supramolecular Capsules Derived from Calixpyrrole Scaffolds, Isr. J. Chem., 2011, 51, 710-724.

${ }^{5}$ L. Adriaenssens, C. Estarellas, A. Vargas Jentzsch, M. Martinez Belmonte, S. Matile, and P. Ballester, Quantification of Nitrate- $\pi$ Interactions and Selective Transport of Nitrate Using Calix[4]pyrroles with Two Aromatic Walls, J. Am. Chem. Soc., 2013, 135, 8324-8330; I.-W. Park, J. Yoo, B. Kim, S. Adhikari, S. K. Kim, Y. Yeon, C. J. E. Haynes, J. L. Sutton, C. C. Tong, V. M. Lynch, J. L. Sessler, P. A. Gale, and C.-H. Lee, Oligoether-Strapped Calix[4]pyrrole: An Ion-Pair Receptor Displaying Cation-Dependent Chloride Anion Transport, Chemistry, 2012, 18, 2514-23.

${ }^{6}$ G. Gil-Ramírez, J. Benet-Buchholz, E. C. Escudero-Adán, and P. Ballester, Solid-state SelfAssembly of a Calix[4]pyrrole-Resorcinarene Hybrid into a Hexameric Cage, J. Am. Chem. Soc., 2007, 129, 3820-3821.

${ }^{7}$ L. R. MacGillivray and J. L. Atwood, A chiral spherical molecular assembly held together by 60 hydrogen bonds, Nature, 1997, 389, 469-472; T. Gerkensmeier, W. Iwanek, C. Agena, R. Fröhlich, S. Kotila, C. Näther, and J. Mattay, Self-assembly of 2,8,14,20Tetraisobutyl-5,11,17,23-tetrahydroxyresorc[4]arene, Eur. J. Org. Chem., 1999, 2257-2262; J. L. Atwood, L. J. Barbour, and A. Jerga, Organization of the interior of molecular capsules by hydrogen bonding, Proc. Natl. Acad. Sci. U.S.A., 2002, 99, 4837-4841.

${ }^{8}$ S. Slovak, T. Evan-Salem, and Y. Cohen, Self-assembly of a Hexameric Aggregate of a Lipophilic Calix[4]pyrrole-Resorcinarene Hybrid in Solution: A Diffusion NMR Study, Org. Lett., 2010, 12, 4864-4867.

${ }^{9}$ A. Galán, E. C. Escudero-Adán, A. Frontera, and P. Ballester, Synthesis, Structure, and Binding Properties of Lipophilic Cavitands Based on a Calix[4]pyrrole-Resorcinarene Hybrid Scaffold, J. Org. Chem., 2014, 79, 5545-5557.

${ }^{10}$ R. H. Müller, R. Shegokar, and C. M. Keck, 20 Years of Lipid Nanoparticles (SLN \& NLC): Present State of Development \& Industrial Applications, Curr. Drug. Discov. Technol., 2011, 8, 207-227; R. H. Müller, M. Radtke, and S. A. Wissing, Solid lipid nanoparticles (SLN) and nanostructured lipid carriers (NLC) in cosmetic and dermatological preparations, Adv. Drug Deliv. Rev., 2002, 54, S131-S155.

${ }^{11}$ M. Skiba, D. Wouessidjewe, A. Coleman, H. Fessi, J.-P. Devissaguet, D. Duchene, and F. Puisieux, Preparation and use of novel cyclodextrin-based dispersible colloidal systems in the form of nanospheres, US Patent 5718905, 1998. 
12 A. Dubes, H. Parrot-Lopez, P. Shahgaldian, and A. W. Coleman, Interfacial interactions between amphiphilic cyclodextrins and physiologically relevant cations, J. Colloid Interface Sci., 2003, 259, 103-111.

${ }^{13}$ P. Shahgaldian, E. Da Silva, A. W. Coleman, B. Rather, and M. J. Zaworotko, Para-acylcalix-arene based solid lipid nanoparticles (SLNs): a detailed study of preparation and stability parameters, Int. J. Pharm., 2003, 253, 23-38.

${ }^{14}$ E. Houel, A. Lazar, E. Da Silva, A. W. Coleman, A. Solovyov, S. Cherenok, and V. I. Kalchenko, Interfacial Interactions of Cations with Amphiphilic Dihydroxyphosphonyl-calix[4]-arene Mesosystems, Langmuir, 2002, 18, 1374-1379; P. Shahgaldian, M. Cesario, P. Goreloff, and A. W. Coleman, Para-acyl calix[4]arenes: amphiphilic self-assembly from the molecular to the mesoscopic level, Chem. Commun., 2002, 326-327; P. Shahgaldian, M. A. Sciotti, and U. Pieles, Amino-substituted amphiphilic calixarenes: self-assembly and interactions with DNA, Langmuir, 2008, 24, 8522-8526; P. Shahgaldian, A. W. Coleman, S. Kuduva, and M. J. Zaworotko, Amphiphilic behavior of an apparently non-polar calixarene, Chem. Commun., 2005, 11, 1968-1970.

${ }^{15}$ J. Gualbert, P. Shahgaldian, A. Lazar, and A. W. Coleman, Solid Lipid Nanoparticles (SLNs): Preparation and Properties of Calix[4]resorcinarene-Derived Systems, J. Incl. Phenom. Macrocycl. Chem., 2004, 48, 37-44.

${ }^{16}$ S. Ehrler, U. Pieles, A. Wirth-Heller, and P. Shahgaldian, Surface modification of resorcinarene based self-assembled solid lipid nanoparticles for drug targeting, Chem. Commun., 2007, 2605-2607; K. Helttunen, K. Salorinne, T. Barboza, H. Campos Barbosa, A. Suhonen, and M. Nissinen, Cation binding resorcinarene bis-crowns: the effect of lower rim alkyl chain length on crystal packing and solid lipid nanoparticles, New J. Chem., 2012, 36, 789-795.

${ }^{17}$ K. Helttunen and P. Shahgaldian, Self-assembly of amphiphilic calixarenes and resorcinarenes in water, New J. Chem., 2010, 34, 2704-2714.

${ }^{18}$ M. Pojarova, G. S. Ananchenko, K. A. Udachin, M. Daroszewska, F. Perret, A. W. Coleman, and J. A. Ripmeester, Solid Lipid Nanoparticles of $p$-Hexanoyl Calix[4]arene as a Controlling Agent in the Photochemistry of a Sunscreen Blocker, Chem. Mater., 2006, 18, 5817-5819; A. W. Coleman, S. Jebors, P. Shahgaldian, G. S. Ananchenko, and J. A. Ripmeester, para-Acylcalix[n]arenes: from molecular to macroscopic assemblies, Chem. Commun., 2008, 2291-2303. 
${ }^{19}$ S. Jebors, A. Leydier, Q. Wu, B. B. Ghera, M. Malbouyre, and A. W. Coleman, Solid lipid nanoparticles (SLNs) derived from para-acyl-calix[9]-arene: preparation and stability, $J$. Microencapsul., 2010, 27, 561-571.

${ }^{20} \mathrm{~J}$. N. Israelachvili, Intermolecular and surface forces, $3^{\text {rd }}$ ed., Academic Press, UK, 2011.

${ }^{21}$ F. Ganachaud and J. L. Katz, Nanoparticles and nanocapsules created using the Ouzo effect: Spontaneous emulsification as an alternative to ultrasonic and high-shear devices, ChemPhysChem, 2005, 6, 209-216.

${ }^{22}$ I. Montasser, P. Shahgaldian, F. Perret, and A. W. Coleman, Solid Lipid NanoparticleBased Calix[n]arenes and Calix-Resorcinarenes as Building Blocks: Synthesis, Formulation and Characterization, Int. J. Mol. Sci., 2013, 14, 21899-21942;

${ }^{23}$ B. J. Berne, and R. Pecora, Dynamic light scattering with applications to chemistry, biology and physics, Dover Publications, Inc., Mineola, N.Y., 2000.

${ }^{24}$ V. Filipe, A. Hawe, and W. Jiskoot, Critical evaluation of nanoparticle tracking analysis (NTA) by NanoSight for the measurement of nanoparticles and protein aggregates, Pharm. Res., 2010, 27, 796-810; A. Malloy, Count, size and visualize nanoparticles, Mater. Today, 2011, 14, 170-173.

${ }^{25}$ M. Yusa, G. P. Mathur, and R. A. Stager, Viscosity and Compression of Ethanol-Water Mixtures for Pressures up to 40000 psig, J. Chem. Eng. Data, 1977, 22, 32-35.

${ }^{26}$ J. M. Deutch and I. Oppenheim, The Concept of Brownian Motion in Modern Statistical Mechanics, Faraday Discuss. Chem. Soc., 1987, 83, 1-20.

${ }^{27}$ D. S. Lemons and A. Gythiel, Paul Langevin's 1908 paper "On the Theory of Brownian Motion" ["Sur la théorie du mouvement brownien," C. R. Acad. Sci. (Paris) 146, 530-533 (1908)], Am. J. Phys., 1997, 65, 1079-1081.

${ }^{28}$ J. A. Gallego-Urrea, J. Tuoriniemi, and M. Hassellöv, Applications of particle-tracking analysis to the determination of size distributions and concentrations of nanoparticles in environmental, biological and food samples, TrAC - Trends Anal. Chem., 2011, 30, 473-483.

${ }^{29}$ W. C. Griffin, Calculation of HLB values of non-ionic surfactants, J. Soc. Cosmet. Chem., $1954, \mathbf{5}, 249-256$.

${ }^{30}$ H. Saveyn, B. De Baets, O. Thas, P. Hole, J. Smith, and P. Van der Meeren, Accurate particle size distribution determination by nanoparticle tracking analysis based on 2-D Brownian dynamics simulation, J. Colloid Interface Sci., 2010, 352, 593-600.

${ }^{31}$ D. F. Evans, H. Wennerström, The colloidal domain: where physics, chemistry, biology, and technology meet, $2^{\text {nd }}$ ed., Wiley-VCH, UK, 1999. 
${ }^{32}$ S. Yoshimura, S. Shirai, and Y. Einaga, Light-Scattering Characterization of the Wormlike Micelles of Hexaoxyethylene Dodecyl $\mathrm{C}_{12} \mathrm{E}_{6}$ and Hexaoxyethylene Tetradecyl $\mathrm{C}_{14} \mathrm{E}_{6}$ Ethers in Dilute Aqueous Solution, J. Phys. Chem. B, 2004, 108, 15477-15487.

${ }^{33}$ O. Gawron, M. Duggan, and C. J. Grelecki, Manometric Determination of Dissociation Constants of Phenols, Anal. Chem., 1952, 24, 969-970.

${ }^{34}$ A. N. Zhukov, L. V. Duda, and I. L. Fedorova, Effect of the Surface Conductance on Electrokinetic Potential Measured in Nonaqueous Media, Colloid J., 2001, 63, 301-305. 